\title{
SPINAL ANAESTHESIA USING ISOBARIC LEVOBUPIVACAINE ALONE AND WITH FENTANYL FOR LOWER ABDOMINAL SURGERY- A RANDOMISED DOUBLE BLINDED CONTROLLED TRIAL
}

\author{
1 Professor, Department of Anaesthesiology, RNT Medical College, Udaipur, Rajasthan. \\ ${ }^{2}$ Assistant Professor, Department of Anaesthesiology, RNT Medical College, Udaipur, Rajasthan. \\ ${ }^{3}$ Senior Resident, Department of Anaesthesiology, RNT Medical College, Udaipur, Rajasthan. \\ $4 J u n i o r$ Resident, Department of Anaesthesiology, RNT Medical College, Udaipur, Rajasthan. \\ 5 Professor, Department of Anaesthesiology, RNT Medical College, Udaipur, Rajasthan. \\ 6Junior Resident, Department of Anaesthesiology, RNT Medical College, Udaipur, Rajasthan. \\ 7 Junior Resident, Department of Anaesthesiology, RNT Medical College, Udaipur, Rajasthan.
}

Devendra Verma ${ }^{1}$, Ravindra Kumar Gehlot², Vineeta Goda ${ }^{3}$, Meenakshi Machhar ${ }^{4}$, Udita Naithani $^{5}$, Dinesh Didwania 6 , Snigdha Singh ${ }^{7}$

\section{BACKGROUND}

\section{ABSTRACT}

Levobupivacaine has equal potency as bupivacaine but lower CVS and CNS toxicity. Aim was to evaluate clinical efficacy of isobaric levobupivacaine with or without fentanyl in spinal anaesthesia for inguinal hernia surgeries regarding sensory-motor block characteristics, haemodynamic profile and complications.

\section{MATERIALS AND METHODS}

After approval from institutional ethical committee (IEC) and informed written consent, a randomised double blinded controlled trial was conducted during 1 year period. 60 patients of ASA I-II of age 20-60 years, weight 40-90 kg, were divided into two groups 30 each, to receive either $4 \mathrm{~mL}$ of $0.5 \%$ isobaric levobupivacaine (group L) or $4 \mathrm{~mL}$ of $0.5 \%$ isobaric levobupivacaine $+25 \mu \mathrm{g}$ fentanyl (group LF) intrathecally. Exclusion criteria- uncooperative patient and patient refusal, h/o allergy to study drugs, vertebral deformity, morbid obesity and any other associated systemic illness. Patients were monitored for sensory and motor block characteristics, postoperative analgesia, haemodynamics, side effects and complications. Data analysed by using Student $\mathrm{t}$ test and Chi square test; $\mathrm{p}<0.05$ was considered as statistically significant.

\section{RESULTS}

Onset of sensory block and time to reach peak sensory level was shorter in group LF (6.40 \pm 0.67 and $7.17 \pm 0.79$ min. $)$ as compared to group L ( $8.20 \pm 0.76$ and $9.27 \pm 0.98 \mathrm{~min}$.) ( $\mathrm{p}=0.00)$. Onset of motor block was shorter in group LF ( $8.57 \pm 1.04 \mathrm{~min}$.) compared to group L (9.10 $\pm 0.92 \mathrm{~min}$.). Duration of analgesia was prolonged in Group LF (152 $\pm 3.89 \mathrm{~min}$.) compared to Group L (142.30 $\pm 18.4 \mathrm{~min}$.), ( $\mathrm{p}=0.007)$. Haemodynamic variables and demographic data were comparable in both groups.

\section{CONCLUSION}

Isobaric levobupivacaine in spinal anaesthesia produces effective sensory-motor block of sufficient duration with stable haemodynamic profile in lower abdominal surgeries. Addition of fentanyl to levobupivacaine results in shortening of onset time, increased peak sensory level and prolonged duration of analgesia.

\section{KEYWORDS}

Levobupivacaine, Fentanyl, Inguinal Hernia Surgeries, Spinal Anaesthesia.

HOW TO CITE THIS ARTICLE: Verma D, Gehlot RK, Goda V, et al. Spinal anaesthesia using isobaric levobupivacaine alone and with fentanyl for lower abdominal surgery- a randomised double blinded controlled trial. J. Evolution Med. Dent. Sci. 2017;6(36):29682972, DOI: $10.14260 / \mathrm{Jemds} / 2017 / 639$

\section{BACKGROUND \\ Spinal anaesthesia is a preferred technique for patients undergoing infra-umbilical surgery as it provides adequate sensory-motor blockage with faster onset. ${ }^{1}$ Additional advantages of spinal anaesthesia are blunting of stress response, decrease in intraoperative blood loss, thromboembolic phenomenon and postoperative hypoxic episodes. $^{2}$}

Financial or Other, Competing Interest: None.

Submission 27-03-2017, Peer Review 21-04-2017,

Acceptance 27-04-2017, Published 04-05-2017.

Corresponding Author:

Dr. Ravindra Kumar Gehlot,

Q. N. 03, Dilshad Bhawan

69 Chetak Circle,

Udaipur-313001, Rajasthan.

E-mail: dr.rgehlot.2010@gmail.com

DOI: $10.14260 /$ jemds $/ 2017 / 639$
When additives like opioid analogues are combined with local anaesthetics in spinal anaesthesia, they improve the onset of action, prolong the duration of sensory block and improve the quality of perioperative analgesia without prolonging the duration of motor block. ${ }^{3}$

Bupivacaine is still the most commonly used local anaesthetic agent. However, cases have been reported where unintentional intravascular injection during neuraxial anaesthesia resulting in cardiac arrest with difficult resuscitation.

Cardio/neurotoxicity of bupivacaine is mainly related to dextro isomer. Therefore, pure levo isomer is now being investigated. Levobupivacaine is a recently introduced levo isomer which has almost equal potency as bupivacaine, but lower cardiovascular and nervous system toxicity. ${ }^{4}$ It is commercially available as isobaric levobupivacaine and has been investigated in spinal anaesthesia in clinical studies in doses ranging $5 \mathrm{mg}$ to $17.5 \mathrm{mg}$ and found effective for lower abdominal surgeries, ${ }^{5}$ lower limb surgery, ${ }^{6}$ caesarean 
section. ${ }^{7}$ In our internet search, we also observed that higher doses of intrathecal bupivacaine $(20 \mathrm{mg})$ has been extensively evaluated but data regarding clinical efficacy and safety profile of high dose levobupivacaine $(20 \mathrm{mg})$ are lacking. There is also a need for evaluating the effect of adding fentanyl to such maximum doses $(20 \mathrm{mg})$ of levobupivacaine in clinical practice. Therefore, we designed this study to evaluate clinical efficacy of $20 \mathrm{mg}$ isobaric levobupivacaine

(4 $\mathrm{mL}$ of $0.5 \%$ ) in spinal anaesthesia for inguinal hernia surgery regarding sensorymotor block characteristics, haemodynamic profile, success rate and complications. The effect of addition of $25 \mu \mathrm{g}$ of fentanyl to it was also evaluated. Our ultimate aim was if isobaric levobupivacaine can produce effective spinal anaesthesia, being less cardiotoxic, it could become a better alternative to bupivacaine.

\section{MATERIALS AND METHODS}

Following the approval of the institutional ethical committee and informed written consent from patients, a randomised, double blinded, controlled trial was conducted in Department of Anaesthesiology, M B Govt. Hospital attached to RNT Medical College, Udaipur (Raj) during one year period (Jan. 2014 to Dec. 2014).

\section{Exclusion Criteria}

Included a history of allergy to study drugs, uncontrolled hypertension, vertebral deformities, neurologic disease, endocrine disease, uncooperative patients and patient refusal, morbid obesity, bleeding diathesis, severe hypovolaemia, raised intracranial pressure, infection at the site of injection, severe stenotic valvular heart disease, ventricular outflow obstruction and any other associated systemic illness.

Sixty patients of ASA physical status I-II of both sexes, posted for inguinal hernia repair with mesh, aged between 20-60 years, weight 40-90 kg and height $140-170 \mathrm{~cm}$ were recruited. All patients under study were subjected to a detailed pre-anaesthetic examination and investigations were carried out accordingly during this evaluation. All patients were randomised into two groups (30 patients in each group) by sealed envelope technique based on intrathecal dose regime as follows: Group $\mathrm{L}(\mathrm{n}=30): 4 \mathrm{~mL}$ of $0.5 \%$ isobaric levobupivacaine (20 mg), Group LF ( $\mathrm{n}=30$ ): $4 \mathrm{~mL}$ of $0.5 \%$ isobaric levobupivacaine $(20 \mathrm{mg})+25 \mu \mathrm{g}$ fentanyl.

\section{Blinding}

To ensure double blindness to the study, two anaesthesiologists were involved in the study. Drugs were prepared by one anaesthesiologist, who performed subarachnoid block and was not involved further in the study. The data was recorded by another anaesthesiologist, was unaware of group allocation. Patients, surgeon and nursing staff of postoperative ward were also unaware of group allocation.

The patients were kept fasting overnight and received tablet alprazolam $0.25 \mathrm{mg}$ orally the night before operation. Before the commencement of anaesthesia, patients were explained about the methods of sensory and motor assessments. Standard monitoring was done throughout the operation. ECG and pulse-oximetry $\left(\mathrm{SpO}_{2}\right)$ were monitored continuously, while non-invasive blood pressure (NIBP) was measured at 5-min. intervals. After peripheral intravenous access with $18 \mathrm{G} \mathrm{IV}$ cannula patients were preloaded with 10 mL kg-1 infusion of Ringer lactate, and injection midazolam 1 $\mathrm{mg}$ IV and injection ondansetron $4 \mathrm{mg}$ IV were given as premedication. Heart rate and arterial pressure were measured and noted as baseline value.

All patients received spinal anaesthesia via midline approach at $\mathrm{L}_{3}-\mathrm{L}_{4}$ intervertebral space using 25G Quincke spinal needle with patients in the lateral decubitus position. At the end of injection, time was noted as time of intrathecal injection and taken as zero $\left(\mathrm{t}_{0}\right)$. All time intervals were calculated from this point of time. The patient was placed in supine position to achieve bilateral block. Heart rate (HR), systolic blood pressure (SBP) and diastolic blood pressure (DBP) were monitored intraoperatively. Throughout the procedure all patients received oxygen at $5 \mathrm{~L} / \mathrm{min}$. through ventimask. Fluid and blood were administered as per need.

Sensory and motor block were assessed in every $2 \mathrm{~min}$. up to $15 \mathrm{~min}$. The level of sensory block was evaluated by loss of pinprick sensation with 24G hypodermic needle. Grading score for sensory block (Gromley and Hill 1996) was Grade 0 - Normal sensation, Grade 1 - Blunted sensation, Grade 2 - No sensation. Grade-2 was taken as onset of sensory block.

\section{Grading for Motor Block was done According to Modified Bromage Score}

0 - Able to flex hips/knee/ankle (No motor block)

1 - Able to move knee/unable to raise extended leg (Partial motor block)

2- Able to flex ankle, unable to flex knee (Near complete motor block)

3 - Unable to move any part of lower limb (Complete motor block)

Surgery was initiated when the level of sensory block was reached to $\mathrm{T}_{10}$ thoracic dermatome level or above and attainment of Bromage score of 2 or 3 . If it was not achieved in 15 minutes, it was considered as failed spinal, and general anaesthesia was given and case was excluded from further data analysis.

Haemodynamic parameters (HR, SBP, DBP) were recorded after spinal injection every $3 \mathrm{~min}$. for the first 15 min., then every $5 \mathrm{~min}$. till the end of surgery. Hypotension was categorised as the fall in SBP to less than $90 \mathrm{mmHg}$ and treated with incremental dose of IV mephentermine $6 \mathrm{mg}$ and total dose given in each patient was noted. Bradycardia was defined as heart rate $<60 \mathrm{bpm}$ and treated with IV atropine $0.4 \mathrm{mg}$.

All time intervals were calculated from the time of end of intrathecal injection $\left(\mathrm{t}_{0}\right)$. Onset of sensory block was defined as time to reach sensory block at T10. Peak sensory level was defined as maximum height of sensory block achieved and time required to achieve peak sensory level was also recorded. For sensory block recovery, time taken in regression from peak sensory level to L1 was recorded and considered as effective sensory block duration to carry out destined surgery which was primary outcome of the study.

Time taken for complete sensory regression to S1 was also recorded and defined as total sensory block duration. Maximum Bromage score, Time to achieve maximum Bromage score (motor onset), time taken for regression to Bromage score zero (motor block duration) were also 
recorded. Time of first complaint of pain was noted (duration of analgesia) and rescue analgesic in form of diclofenac injection (75 mg IM) was given, duration of surgery was noted as time of incision to last suture. Occurrence of hypotension, bradycardia, nausea, vomiting, pruritus, headache, arrhythmia or any other complication if occurred was noted and treated accordingly. For intra-operative pain, supplementation was given in form of $30 \mathrm{mg}$ pentazocine IV, if pain persisted supplementation was given in form of ketamine (1 $\mathrm{mg} / \mathrm{kg})$, followed by propofol infusion $(100$ $\mu \mathrm{g} / \mathrm{kg} / \mathrm{min}$.) and if surgery could not be continued with this much supplementation, case was converted to general anaesthesia with intubation.

Clinical efficacy (Success rate) was graded as completely successful (if no supplementation given), almost successful (if pentazocine $30 \mathrm{mg}$ given), partially successful (if ketamine and propofol was given), failure (if converted to general anaesthesia). "Success rate" was calculated in terms of number of cases who achieved adequate spinal anaesthesia which included completely successful and almost successful cases.

\section{Sample Size}

Based on a previous study (Singh et al) ${ }^{8}$ using a power analysis, to detect the difference of 30 minutes in duration of sensory regression to L1 from highest sensory level with a power of $90 \%(\beta)$ and confidence interval of $95 \%(\alpha=0.05)$, a minimum sample size of 27 in each group was required. We enrolled 30 patients in each group to compensate for dropouts.

\section{Statistical Analysis}

Data was entered and analysed with the help of MS Excel and SPSS version 17. Quantitative data was represented as arithmetic Mean, (SD), and analysed by using Student $t$ test. Qualitative data was presented as number, and analysed by Chi square test; $\mathrm{p}<0.05$ was considered as statistically significant.

\section{RESULTS}

Both groups were statistically comparable regarding demographic data (mean age, mean weight, height, sex), ASA grading, diagnosis and duration of surgery (Table 1). Haemodynamic variables $\mathrm{HR}, \mathrm{SBP}, \mathrm{DBP}$, and $\mathrm{SpO}_{2}$ showed no significant change from baseline during intra-operative period and were comparable in two groups, $\mathrm{P}>0.05$.

\section{Sensory Motor Block Characteristics (Table 2)}

Time to reach T10 sensory level (sensory onset) was significantly shorter in Group LF (6.40 $\pm 0.67 \mathrm{~min}$.) as compared to Group L (7.17 \pm 0.79 min. $),(p=0.00)$. Time to reach peak sensory level was also significantly shorter in Group LF (8.20 $\pm 0.76 \mathrm{~min}$.) as compared to Group L $(p=0.00)$. Mean peak sensory level was significantly higher in

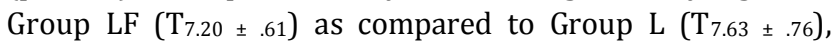
$(p=0.01)$. Median level of peak sensory level was T7 (range T6-T8) in Group LF as compared to T8 (range T6-T8) in Group L. Time to $\mathrm{L} 1$ regression was also significantly longer in Group LF (148 $\pm 3.62 \mathrm{~min}$.) as compared to Group L (140.83 \pm 6.95 min. $),(p=0.00)$. Time to $\mathrm{S} 1$ regression was significantly longer in Group LF (268.833 $\pm 6.11 \mathrm{~min}$.) as compared to Group L (259.0 \pm 8.74 min.), $(p=0.00)$. All patients of both groups achieved Bromage score of 3 signifying complete motor block. Onset of motor block (time to reach Bromage score-3) was significantly shorter in Group LF $(8.57 \pm 1.04 \mathrm{~min}$.) as compared to Group L $(9.10 \pm 0.92$ min.), ( $\mathrm{p}=0.04)$. Duration of motor block as defined by return of Bromage score to 0 was statistically comparable in both groups (222.66 $\pm 12.52 \mathrm{~min}$. in Group L and $223.66 \pm 6.42$ min. in Group LF), (p=0.608). Requirement of first dose of rescue analgesic was significantly delayed in Group LF (152 \pm $3.89 \mathrm{~min}$.) as compared to Group L (142.30 $\pm 18.4 \mathrm{~min}$. $(\mathrm{p}=0.007)$. Incidence of hypotension [Group L 6.67\% $(\mathrm{n}=2)$. Group LF 3.33\% (n=1)], ( $\mathrm{p}=1.00)$ and bradycardia [Group L $6.67 \%(n=2)$, Group LF 3.33\% (n=1)], $(\mathrm{p}=1.00)$ was minimal and statistically comparable in both groups. No other side effects were observed in the study.

\section{Clinical Efficacy (Table 3)}

None of the patient had any complaint of pain intraoperatively in Group LF, hence none of the patient required analgesic supplementation in Group LF. In Group L, 26 patients (86.6\%) required no supplementation, only 4 patients $(13.33 \%)$ complained of pain at the time of peritoneal stretching which was relieved by Inj. Pentazocine $30 \mathrm{mg}$ IV. None of the patient in both groups required Ketamine/Propofol or conversion to general anaesthesia. Rate of supplementation was comparable in both groups $(p=0.112)$. Success rate (clinical efficacy) was calculated as number of cases having "adequate" spinal anaesthesia which included "completely successful" and "almost successful" cases. Incidence of completely successful cases was $86.7 \%$ $(n=26)$ in Group L and 100\% $(n=30)$ in Group LF and incidence of almost successful cases was $13.3 \%(n=4)$ in Group L, this resulted in success rate of $100 \%$ in both groups.

\begin{tabular}{|c|c|c|c|}
\hline Variables & Group L & Group LF & P value \\
\hline Age (years) & $44.36 \pm 14.89$ & $43.13 \pm 5.49$ & 0.672 \\
\hline Weight $(\mathrm{kg})$ & $62.80 \pm 3.78$ & $62.80 \pm 3.78$ & 1.00 \\
\hline Height (cm) & $161.17 \pm 3.06$ & $161.60 \pm 3.95$ & 0.637 \\
\hline $\begin{array}{c}\text { ASA grade } \\
(\mathrm{I} / \mathrm{II})\end{array}$ & $27 / 3$ & $27 / 3$ & 1.00 \\
\hline $\begin{array}{c}\text { Duration of } \\
\text { surgery(min.) }\end{array}$ & $82.07 \pm 7.18$ & $80.00 \pm 5.08$ & 0.20 \\
\hline \multicolumn{4}{|c|}{ Table 1. Demographic Profile } \\
\hline \multicolumn{3}{|c}{} \\
\hline
\end{tabular}

\begin{tabular}{|c|c|c|c|}
\hline Variables & Group L & Group LF & P value \\
\hline $\begin{array}{c}\text { Sensory onset } \\
\left.\text { (Time to } \mathrm{T}_{10}\right) \\
\text { (in min.) }\end{array}$ & $7.17 \pm 0.79$ & $6.40 \pm 0.67$ & 0.00 \\
\hline $\begin{array}{c}\text { Motor onset } \\
\text { (Time to B3) } \\
\text { (in min.) }\end{array}$ & $9.10 \pm 0.92$ & $8.57 \pm 1.04$ & 0.04 \\
\hline $\begin{array}{c}\text { Time to peak } \\
\text { sensory level } \\
\text { (in min.) }\end{array}$ & $9.27 \pm 0.98$ & $8.20 \pm 0.76$ & 0.00 \\
\hline $\begin{array}{c}\text { Peak Mean } \pm \mathrm{SD} \\
\text { sensory } \\
\text { level Median }\end{array}$ & $\mathrm{T}_{7.63 \pm .765} \mathrm{~T}_{8}$ & $\mathrm{~T}_{7.20 \pm .610}$ & 0.01 \\
\hline $\begin{array}{c}\text { Sensory regression } \\
\text { to L1 (in min.) }\end{array}$ & $140.83 \pm 6.95$ & $148 \pm 3.62$ & 0.00 \\
\cline { 1 - 3 } $\begin{array}{c}\text { Sensory regression } \\
\text { to S (in min.) }\end{array}$ & $259.0 \pm 8.74$ & $268.83 \pm 6.11$ & 0.00 \\
\hline
\end{tabular}




\begin{tabular}{|c|c|c|c|}
\hline $\begin{array}{c}\text { Duration of } \\
\text { analgesia (in min.) }\end{array}$ & $142.30 \pm 18.40$ & $152 \pm 3.89$ & 0.007 \\
\hline $\begin{array}{c}\text { Time to regression } \\
\text { to } \mathrm{B}_{0} \text { (Bromage } \\
\text { score 0) (in min.) }\end{array}$ & $222.66 \pm 12.52$ & $223.66 \pm 6.42$ & 0.608 \\
\hline Table 2: Sensory Block and Motor Block Characteristics \\
in Two Groups
\end{tabular}

\begin{tabular}{|c|c|c|c|}
\hline & Success Rate & $\begin{array}{c}\text { Group } \\
L \\
(n=30)\end{array}$ & $\begin{array}{c}\text { Group } \\
\mathbf{L F} \\
(\mathrm{n}=30)\end{array}$ \\
\hline \multirow{2}{*}{ Adequate } & $\begin{array}{c}\text { Completely successful } \\
\text { (if no supplementation } \\
\text { given) }\end{array}$ & $\begin{array}{c}26 \\
(86.7 \%)\end{array}$ & $\begin{array}{c}30 \\
(100 \%)\end{array}$ \\
\hline & $\begin{array}{c}\text { Almost successful } \\
\text { (if pentazocine } 30 \mathrm{mg} \\
\text { given) }\end{array}$ & $\begin{array}{c}4 \\
(13.3 \%)\end{array}$ & $\begin{array}{c}0 \\
(0 \%)\end{array}$ \\
\hline \multirow[t]{2}{*}{ Inadequate } & $\begin{array}{c}\text { Partially successful } \\
\text { (if ketamine and propofol } \\
\text { was given) }\end{array}$ & $\begin{array}{c}0 \\
(0 \%)\end{array}$ & $\begin{array}{c}0 \\
(0 \%)\end{array}$ \\
\hline & $\begin{array}{l}\text { Failure (if converted to } \\
\text { general anaesthesia) }\end{array}$ & $\begin{array}{c}0 \\
(0 \%)\end{array}$ & $\begin{array}{c}0 \\
(0 \%)\end{array}$ \\
\hline
\end{tabular}

All data measured in Mean \pm SD

\section{DISCUSSION}

Spinal anaesthesia using local anaesthetics is a rapid onset and effective sensory and motor blockade technique for infraumbilical surgeries and spinal anaesthesia remains a preferred technique for such surgery. Local anaesthetics block voltage-gated sodium channels thereby interrupting the initiation and propagation of nerve impulses in axons. It has been well documented that a combination of local anaesthetics with opioids has a synergistic analgesic effect when administered intrathecally. Various studies[8,10] reported that addition of fentanyl to LA improves anaesthesia quality and prolongs postoperative analgesia without prolonging motor block. Levobupivacaine, the pure levo isomer of racemic bupivacaine which has almost similar efficacy but an enhanced safety profile is currently being investigated for spinal anaesthesia. Till the time of planning of this study, none of the study was available which evaluated the clinical efficacy and safety profile of high doses $(20 \mathrm{mg})$ of levobupivacaine alone and with fentanyl. Our study clearly demonstrated that levobupivacaine in dose of $20 \mathrm{mg}$ produced effective sensory-motor blockade of sufficient duration for inguinal hernia surgery. Addition of fentanyl improved the sensory and motor block characteristics in terms of faster onset, higher peak sensory level, prolongation of duration of sensory block and postoperative analgesia.

In our study, time to reach T10 sensory level was $7.17 \pm$ $7.9 \mathrm{~min}$. and time to reach peak sensory level was $9.27 \pm 0.78$ min. in levobupivacaine group. With addition of fentanyl 25 $\mu \mathrm{g}$ to levobupivacaine intrathecally resulted in onset time to T10 sensory level of $6.40 \pm 0.67 \mathrm{~min}$. and time to reach peak sensory level was $8.20 \pm 0.76 \mathrm{~min}$. Akan et al ${ }^{9}$ using $7.5 \mathrm{mg}$ levobupivacaine and combining it with $25 \mu \mathrm{g}$ fentanyl or 2.5 $\mu \mathrm{g}$ sufentanil also reported significantly shorter onset time to reach T10 sensory level with addition of fentanyl and sufentanil than levobupivacaine alone. Ozylikan et al ${ }^{10}$ compared $2.2 \mathrm{~mL}$ of levobupivacaine plain with $10 \mu \mathrm{g}$ fentanyl or $2.5 \mu$ g fentanyl as adjuvant in spinal anaesthesia for caesarean section and demonstrated that addition of fentanyl resulted in time to T10 sensory level of 2.50 (1-10) min in combination group $\mathrm{F}$ as compared to $11(6-15) \mathrm{min}$. with levobupivacaine alone. Time to reach peak sensory level was $7.52 \pm 2.18 \mathrm{~min}$. in Group F as compared to $12.70 \pm 3.74$ min in Group C (levobupivacaine alone) which was significantly longer in Group C $(\mathrm{P}<0.05)$. Above results demonstrate that adding fentanyl to levobupivacaine has potentiating effect on sensory block onset time which may or may not reach statistical significance.

Fentanyl acts on $\mu$ receptor in the spinal cord and exerts its action by opening $\mathrm{K}+$ channels and reducing $\mathrm{Ca}++$ influx resulting in inhibition of transmitter release. This could be the reason that patients in whom fentanyl was given along with levobupivacaine in spinal anaesthesia had significantly faster sensory block onset as compared to patients receiving levobupivacaine alone as observed in our study and by other studies.[9,10]

All patients in both groups achieved Bromage score of 3 signifying complete motor blockade in present study. Addition of fentanyl to levobupivacaine resulted in significant shortening in onset time of motor block, though this difference of $1 \mathrm{~min}$. has not much clinical significance. In present study, duration of motor block was statistically comparable in both groups.

Akan et $\mathrm{al}^{9}$ concluded that combining lower doses of levobupivacaine with fentanyl and sufentanil provides shorter duration of motor block and prolonged analgesia time. Similarly, Cuvas et al ${ }^{11}$ demonstrated that duration of motor block was shorter in fentanyl group. This occurred because in fentanyl groups they used lower dose of levobupivacaine. We used similar dose of levobupivacaine in both groups, therefore motor block duration was comparable in both groups. In present study, time for first rescue analgesic (duration of analgesia) was significantly longer in Group LF as compared to Group L, and this result was consistent with those obtained by Akan et $\mathrm{al}^{9}$ and Ozylikan et $\mathrm{al}^{10}$. In present study, two groups were statistically comparable regarding vital parameters, which confirms the haemodynamic stability property of isobaric levobupivacaine. Akan et al,9 Cuvas et al,11 Borazen et al ${ }^{12}$ studied levobupivacaine with fentanyl and reported that there was no significant difference in haemodynamic data including SBP, DBP, MAP, HR, SpO2 ( $p>0.05)$. This showed that isobaric levobupivacaine can be used safely in spinal anaesthesia without affecting haemodynamic variables significantly. Chattopadhyay et $\mathrm{al}^{1}$ concluded that addition of fentanyl to levobupivacaine does not increase the incidence of bradycardia. Akan et $\mathrm{al}^{9}$ also concluded that there was no significant difference in the mean heart rate and blood pressure in plain levobupivacaine group and levobupivacaine plus fentanyl group. Similar results were reported by Cuvas et al ${ }^{11}$ and Lee et al. ${ }^{13}$

None of the patient in our both groups developed side effects like pruritus, nausea, vomiting, tremors, arrhythmia, respiratory depression except for a single episode of hypotension and bradycardia. However, pruritus as a side effect of intrathecal fentanyl, hypotension and bradycardia were reported by previous studies.[9,11]

In our study, none of the patient required anaesthesia supplementation in Group LF as compared to 4 (13.33\%) 
patients in Group L who complained of pain and discomfort at the time of stretching of peritoneum which was relieved by pentazocine $30 \mathrm{mg}$, and surgery was completed without further supplementation. Similarly, Cuvas et al ${ }^{11}$ found that none of their subject required analgesics but Ozylikan et al 10 reported that intravenous fentanyl demand and sedation requirement were significantly higher in levobupivacaine alone Group C $(\mathrm{p}<0.05)$. Opioids have potentiating effect on sensory block characteristics which might be the reason that supplementation was not required in fentanyl treated group.

Incidence of completely successful cases (no supplementation) was $100 \%$ in Group LF and $86.7 \%$ in Group $\mathrm{L}$, remaining $13.3 \%$ patients of Group $\mathrm{L}$ were categorised as almost successful cases (single dose of opioid supplementation). Similarly, Cuvas et al11 conducted a study using $0.5 \%$ of $2.5 \mathrm{~mL}$ of levobupivacaine alone (Group L) and $0.5 \%$ of $2.2 \mathrm{~mL}$ of levobupivacaine with $15 \mu \mathrm{g}$ fentanyl (Group LF) in spinal anaesthesia for patients undergoing TURP and reported that none of the patient required analgesia and anxiolysis intra-operatively ( $p>0.05)$.

\section{Limitations}

Our study compared high dose levobupivacaine with and without fentanyl in spinal anaesthesia for inguinal hernia surgeries which can be carried out if target $\mathrm{T} 10$ sensory level is achieved. But if surgeries requiring higher peak sensory level were included, success rate could have been different.

\section{CONCLUSION}

Isobaric levobupivacaine $(20 \mathrm{mg})$ in spinal anaesthesia produces effective sensory-motor block of sufficient duration with stable haemodynamic profile to accomplish lower abdominal surgeries (inguinal hernia surgery). Addition of fentanyl to levobupivacaine results in significant shortening of onset time, increased height of peak sensory level and significant prolongation of duration of sensory blockade and analgesia. Being less cardio/neurotoxic levobupivacaine seems to be a reasonable alternative to most commonly used agent hyperbaric bupivacaine in spinal anaesthesia for lower abdominal surgery.

\section{REFERENCES}

[1] Chattopadhyay A, Maitra S, Sen S, et al. A study to compare the analgesic efficacy of intrathecal bupivacaine alone with intrathecal bupivacaine midazolam combination in patients undergoing elective infraumbilical surgery. Anesthesiol Res Pract 2013;2013:567134.

[2] Naghibi K, Saryazdi H, Kashefi P, et al. The comparison of spinal anaesthesia with general anaesthesia on the postoperative pain scores and analgesic requirements after elective lower abdominal surgery a randomised, double blind study. J Res Med Sci 2013;18(7):543-8.
[3] Varun S, Srivastava M, Maurya I, et al. A clinical prospective, randomised study to compare intrathecal isobaric bupivacaine - fentanyl and isobaric ropivacaine-fentanyl for lower abdominal and lower limb surgeries. Anaesth Pain and Intensive Care 2012;16(3):237-42.

[4] Ngamprasertwong P, Udomtecha D, Charulaxananan S, et al. Levobupivacaine versus racemic bupivacaine for extradural anesthesia for cesarean delivery. J Med Assoc Thai 2005;88(11):1563-8.

[5] Mantouvalou M, Ralli S, Arnaoutoglou H, et al. Spinal anesthesia: comparison of plain ropivacaine, bupivacaine and levobupivacaine for lower abdominal surgery. Acta Anaesth Belg 2008;59(2):65-71.

[6] Mehta A, Gupta V, Wakhloo R, et al. Comparative evaluation of intrathecal administration of newer local anaesthetic agents ropivacaine and levobupivacaine with bupivacaine in patients undergoing lower limb surgery. The Internet Journal of Anesthesiology 2007;17(1):1-7.

[7] Guler G, Gokhan C, Ayse U, et al. A comparison of spinal anesthesia with levobupivacaine and hyperbaric bupivacaine for cesarean sections: a randomised trial. 0 J Anes 2012;2:84-9.

[8] Singh H, Yang J, Thornton K, et al. Intrathecal fentanyl prolongs sensory bupivacaine spinal block. Can J Anaesth 1995;42(11):987-91.

[9] Akan B, Yagan O, Bilal B, et al. Comparison of levobupivacaine alone and in combination with fentanyl and sufentanil in patients undergoing transurethral resection of prostate. J Res Med Sc 2013;18(5):378-82.

[10] Ozyilkan NB, Aysu K, Mesut S, et al. Comparison of intrathecal levobupivacaine combined with sufentanil, fentanyl, or placebo for elective caesarean section: a prospective, randomised, double-blind, controlled study. Curr Ther Clin Exp 2013;75:65-7.

[11] Cuvas O, Basar H, Yeygel A, et al. Spinal anesthesia for transurethral resection operations: levobupivacaine with or without fentanyl. Middle East J Anesthesiol 2010;20(4):547-52.

[12] Borazan H, Davarci I, Kececioglu A, et al. The effects of low dose levobupivacaine with or without sufentanil intrathecally in transurethral resection of prostate. Eur J Gen Med 2011;8(2):134-40.

[13] Lee YY, Muchhal K, Chan CK, et al. Levobupivacaine and fentanyl for spinal anaesthesia: a randomised trial. Eur J Anaesthesiol 2005;22(12):899-903. 